\title{
SOBRE A PESQUISA CIENTÍFICA EM DIREITO'
}

Cláudio Souto ${ }^{\mathrm{ii}}$

Sumário: 1 A pesquisa em direito e seus níveis de rigor científico. 2 A pesquisa científico-social do direito: sua situação atual e a busca de rigor teórico-explicativo. 3 Tentando ir além da pobreza teórico-geral da pesquisa sociojurídica: consideração preliminar. 4 Os passos práticos para a busca da explicação científico-social mais abrangente da pesquisa em direito. 5 Postulados de interesse explicativo mais geral para a pesquisa científica em direito. 6 Alguns teoremas de interesse explicativo mais geral para a pesquisa em direito. Referências.

\section{Resumo}

Lidando com a pesquisa científica em Direito, o artigo mostra como se dá, deterministicamente, a atração e a repulsão nas interações mentais e sociais, e propõe um modelo teórico unificado mental-social, assim como mostra que o conhecimento científico já adquirido nessa área pode ser aplicado à vida prática.

Palavras-chave: Pesquisa científico-social do Direito. Postulados fundamentais. Sistema sociointerativo.

\footnotetext{
i Trabalho elaborado para o IV Congresso Nacional da Associação Brasileira de Pesquisadores em Sociologia do Direito (ABraSD), Recife, 11-13 de novembro de 2013 (Congresso em homenagem a Luciano Oliveira). Um resumo do escrito foi apresentado oralmente em 13 de novembro de 2013 como conferência de encerramento do Congresso.

${ }^{i i}$ Doutor, Livre-Docente e ex-regente de cátedra pela Faculdade de Direito da Universidade Federal de Pernambuco, Doutor em Ciências Sociais pela Faculdade de Sociologia da Universidade de Bielefeld, Alemanha. Professor Titular Emérito de Sociologia do Direito da Universidade Federal de Pernambuco. Antigo Professor das Pós-Graduações em Direito, Filosofia e Sociologia desta UFPE. Antigo Professor Visitante das Universidades de Columbia (Nova Iorque, EUA) e de Köln (Colônia, Alemanha).
} 


\subsection{TEORIA SOCIOJURÍDICA NACIONAL}

\begin{abstract}
By dealing with scientific research in law, the article shows how the attraction and the repulsion in mental and social interactions happens deterministically, and proposes a mental-social united theoretical model, as well as shows that the already acquired scientific knowledge in this field can be applied to practical life.
\end{abstract}

Keywords: Research scientific and social rights. Fundamental postulates. Socio-interactive system.

\section{A PESQUISA EM DIREITO E SEUS NÍVEIS DE RIGOR CIENTÍFICO}

A pesquisa em direito apresenta-se usualmente dentro dos limites da chamada Dogmática Jurídica: a pesquisa é apenas bibliográfica e observacional simples. Como saber dedicado à interpretação e à sistematização de normas tidas como jurídicas ${ }^{1}$, volteja basicamente em torno de leis e de decisões judiciais monocráticas ou colegiadas - e em torno de uma bibliografia correspondente. Pesquisas de teoria pura quanto ao direito são bem menos frequentes, mesmo em termos de uma visão formal, lógico-normativa, do jurídico.

O mencionado tipo de pesquisa, apenas bibliográfico e observacional simples, usufrui, direta ou indiretamente, dos prestígios social e midiático dos poderes legislativo e judiciário. Todavia não desfruta de um prestígio significativo do ponto de vista científico-substantivo, já que seu rigor metodológico, nesse ponto de vista, é muito escasso. E só um tanto excepcionalmente o referido tipo de pesquisa dogmática tem-se fundamentado em dados substantivos de pesquisa científica produzidos em outras áreas do saber.

De fato, geralmente a perspectiva de pesquisa dogmática do direito tem-se situado numa atitude de isolamento em relação às ciências substantivas, sejam estas ciências da natureza, ou, até, ciências do social. O que soa estranho, pois ninguém nega seja o jurídico um fenômeno social. Em consequência, soa também estranho que um Centro de Ciências Jurídicas tivesse, por meio século, relutado em acolher, como coisa sua - e não só como algo determinado por portaria ministerial -, uma disciplina que se intitule Sociologia do Direito ou Sociologia Jurídica. Pois esta última é, decerto, uma ciência do jurídico.

A atitude de isolamento é sociologicamente explicável: tudo parece indicar que se trataria de caso clássico de resistência à mudança em virtude do poder dos interesses investidos no status

AARNIO, Aulis; ARNAUD-DUC, Nicole. Dogmatique juridique. Dictionnaire Encyclopédique de Théorie et de Sociologie du Droit, sous la direction de André-Jean Arnaud. Paris: Librairie Générale de Droit et de Jurisprudence, 1993. p. 188. 


\subsection{TEORIA SOCIOJURÍDICA NACIONAL}

quo intelectual e prático.

Empreendeu-se, contudo, recentemente, por iniciativa de Artur Stamford, Germano Schwartz e Marcelo Mello, a promissora constituição de uma Associação Brasileira de Pesquisadores em Sociologia do Direito (ABraSD). acolher, como coisa sua - e não só como algo determinado por portaria ministerial -, uma disciplina que se intitule Sociologia do Direito ou Sociologia Jurídica. Pois esta última é, decerto, uma ciência do jurídico.

Fechada por si mesma nos horizontes limitados de investigação a que se circunscreve, e carente, por si mesma, de métodos e técnicas de pesquisa empírica, a pesquisa dogmática do direito representa um primeiro nível investigatório destituído de rigor científico substantivo significativo, se bem que atinja, não raro, excepcional rigor lógico-formal, rigor este que Max Weber, como sociólogo, enfatiza ${ }^{2}$.

Já o conhecimento científico-substantivo começa onde há o comprovável pela observação controlada por métodos e técnicas de pesquisa empírica (fática). E, por ser assim baseado na observação controlada dos fatos, é o conhecimento menos inseguro que se possa obter. Desse modo, as perspectivas científico-substantivas que relacionem o mental e o direito (Psicologia Jurídica) e o social e o direito (por exemplo, Sociologia do Direito, Antropologia Jurídica, Economia e Direito), poderão apresentar significativo rigor metodológico.

Num mundo acentuadamente científico e tecnológico como o de hoje, não podemos pensar apenas filosoficamente sobre o mental, o social e o direito. Por mais brilhante e abrangente que seja esse pensamento filosófico, contudo, por definição, não é comprovável por métodos e técnicas de pesquisa empírica.

As perspectivas científico-substantivas que relacionem o mental e o direito, ou que relacionem o social e o direito, podem ser teóricas ou aplicadas. Seja como for, porém, seus horizontes são ainda limitados, sobretudo nos estudos aplicados, desde que não abrangem usualmente uma causação mais geral, comprovada ou comprovável, no que se refere ao mental e ao social.

A busca de causas das causas que sejam comprováveis por pesquisa empírica, com o máximo de abrangência do poder explicativo quanto ao mental e ao social, essa busca se situaria em uma teoria mais geral do mental e do social. E, como se verá, essa perspectiva seria a única capaz de apresentar-se de modo realmente determinístico a propósito do mental e do social, sendo de seu natural rigorosas construções axiomáticas por postulados e teoremas. Postulado é, cientificamente, uma proposição básica comprovada ou comprovável faticamente da qual seria possível deduzir proposições menos gerais (chamadas teoremas).

Naturalmente, tratar-se-ia de um determinismo probabilitário: note-se que um grau maior de probabilidade - como nas proposições determinísticas -, ou menor, de probabilidade, é inarredável em ciência substantiva, que não dispõe de verdades absolutas. Quando a proposição científica é determinística, contém um "sempre", explícito ou implícito, o que significaria que sua probabilidade é muito alta.

Repare-se ainda, preliminarmente, que um "determinismo" de fenômenos mentais ou sociais específicos não seria verdadeiro determinismo, eis que não estaria ao abrigo de exceções invalidantes. Por exemplo, dependendo do que se aceite em determinado momento, pode ser mais agradável (menos desagradável), ao indivíduo ou ao grupo, sacrificar a própria vida ou os bens econômicos do que retê-los.

Como o conhecimento científico é sempre probabilitário, pensar cientificamente será sempre pensar de maneira crítica, dubitativa. E não há criação sem crítica, sem a insatisfação com o status quo do conhecimento. Todavia a recíproca não é verdadeira.

A pesquisa psicológica e a científico-social, na acepção mais básica, seriam então a contestação criativa do pensamento anterior - por menor que seja a margem de criação real.

${ }^{2}$ WEBER, Max. Rechtssoziologie (aus dem manuskript herausgegeben und eingeleitet von Johannes Winckelmann). Neuwied: Hermann Luchterhand Verlag, 1960. p. 102. 


\subsection{TEORIA SOCIOJURÍDICA NACIONAL}

\section{A PESQUISA CIENTÍFICO-SOCIAL DO DIREITO: SUA SITUAÇÃO E A BUSCA DE RIGOR TEÓRICO-EXPLICATIVO}

A perspectiva científico-social do direito não se preocupa, comumente, com uma perspectiva teórica mais geral, embora se mostre, não raro, preocupada com teoria.

Lamentavelmente, porém, esta preocupação com teoria se limita usualmente a uma fundamentação da pesquisa em teorias sociojurídicas da moda intelectual, com pouco espaço para uma contribuição pessoal, criativa, dos pesquisadores.

Neste particular, se acentua o interesse por uma perspectiva teórica marxista e menos geral, de inspiração filosófica dialética (considerandose as contradições existentes no real e suas tendências de síntese), perspectiva essa aplicada sobretudo ao capitalismo. O modelo epistemológico mais nitidamente contraposto, o da abordagem indutiva-dedutiva de natureza causalexplicativa - que se inclinaria por proposições comprováveis mais gerais, básicas e rigorosas, de natureza causal - tem sido academicamente menos popular.

Note-se, entretanto, que a abordagem indutiva-dedutiva de natureza causal-explicativa, a abordagem dialética e a abordagem funcional (relativa a fins) têm isso de comum: todas induzem proposições gerais, das quais passam a deduzir explicativamente. Na verdade são perspectivas diferentes referíveis a uma mesma realidade e, por isso mesmo, reciprocamente complementares.

O caminho básico de todas as ciências seria o indutivo, pois a partir de dados particulares é que podem ser elaboradas leis gerais. E a explicação teórica consiste em deduzir das proposições mais gerais explicativas obtidas por indução.

A hipótese científica é a suposição que se submete à pesquisa dos fatos. As hipóteses podem ser gerais (hipóteses de leis científicas) ou particulares, referidas a fenômenos limitados. Devem dizer respeito à realidade e possuir conteúdo informativo.

De modo básico, a metodologia científica implicaria observar informalmente a realidade, com o mínimo possível de preconceitos, imaginar uma hipótese ou hipóteses comprováveis relativas a ela, comprovar pela experimentação ou, no mínimo, pela observação controlada, se a hipótese ou hipóteses correspondem à realidade.

Ora, em qualquer país, raramente se tenta uma explicação teórica mais geral, e criativa, da pesquisa sociojurídica. Se, como se reconhece, o pensamento sociológico procura não só descrever a realidade social, mas sobretudo explicá-la, contudo a preocupação com proposições causais-explicativas mais gerais é quase sempre ausente em Sociologia e em Sociologia do Direito. Entretanto isso pode ser tentado de modo unitário, elegante e simples.

Simplesmente: generaliza-se um número reduzido de proposições (teses) fundamentais a partir da consideração dos fatos concretos particulares, ou seja, "construídas do empírico para o mais geral” (construídas por indução, pois). Dessas proposições mais gerais são deduzidas (ou são dedutíveis) outras proposições menos gerais (que são, portanto, explicadas pelas mais gerais).

Analogamente, o modelo de explicação científica causal de Hempel-Oppenheim toma descrições de fatos e as deduz logicamente de afirmações em forma de lei.

Com frequência, porém, as pesquisas sociojurídicas não vão além da descrição e de hipóteses setoriais: o que é válido, mas não é tudo, nem é o principal.

Faz-se necessária, na verdade, a crítica à limitação da Sociologia e da Sociologia do Direito ao descritivo e ao setorial, bem como a crítica da "Sociologia Crítica". Esta última tem sido muito crítica com relação ao capitalismo, mas insuficientemente crítica de si mesma, por não aspirar, geralmente, a um maior rigor metodológico. Excetuam-se, todavia, autores marxistas do chamado individualismo metodológico (informam, por exemplo, a este respeito, Levine, Sober e Wright $^{3}$ ).

É digna de lembrança a reação do soviético Jacob Bazarian contra uma "objetividade" marxista que desconsidera o fator humano individual:

[...] No conceito de base material da sociedade nós in- 


\subsection{TEORIA SOCIOJURÍDICA NACIONAL}

cluímos outros fatores determinantes que os sociólogos marxistas, em geral, não levam em consideração, tais como o fator geográfico, o fator demográfico e sobretudo o fator biopsíquico do homem. Este último é, segundo o nosso ponto de vista, o mais importante de todos os fatores, pois, afinal, a história e a sociedade são feitas pelos homens e para os homens. ${ }^{4}$

E, entre nós, Luciano Oliveira, sendo intelectual de formação marxista, não se exime de aceitar, "tanto quanto possível", o princípio da neutralidade axiológica do pesquisador: "[...] ele deverá adotar uma postura metodológica neutra, condição indispensável para a elaboração de um trabalho que se pretenda minimamente científico, sem a qual borraríamos qualquer diferença entre um trabalho acadêmico e o mero discurso ideológico [...]"'.

De fato, o valor que norteia a pesquisa científica será o valor cientificidade, consonância à realidade, inarredável que é, da mente humana, o afetivo-ideativo, e, portanto, a valoração. E, naturalmente, uma neutralidade absoluta quanto a outros valores, será inviável, tratando-se apenas do máximo possível de neutralidade axiológica.

Artur Stamford da Silva alerta oportunamente sobre o termo "criticar", que seria de entendêlo como "crítica construtiva": "O termo 'criticar' não tem o sentido de 'destruir,' 'denegrir', antes de apontar falhas para saná-las. Neste ver, a crítica sempre é construtiva"6.

Por outro lado, não é atitude crítica autenticamente científica a que se fundamente no culto mítico de um autor para criticar outros autores. E, como pessoa humana comum, o homem de ciência pode ser um homem de fé. Porém, na função de cientista, é um homem da dúvida: a atitude crítico-científica substantiva e autêntica duvidará de tudo, inclusive de si mesma. Terá como princípio substantivo, não a exatidão, a certeza, mas a probabilidade maior ou menor. Desse modo é que, como lembrava classicamente Einstein, se as proposições da matemática se referem à realidade, não são exatas, e, se são exatas, não se referem à realidade.

Não se trata de uma atitude preconcebida e sim aberta, sempre à procura do seu erro. As soluções da ciência rigorosa nunca são soluções definitivas - apesar de serem as menos inseguras que se possa ter, por serem comprovadas ou comprováveis pela observação controlada dos fatos.

Cumpre notar que o individualismo como perspectiva política não se confunde com o individualismo metodológico. Este último, em qualquer de suas vertentes, teria, segundo Boudon ${ }^{7}$, como ponto comum, a referência de qualquer fenômeno social ao individual, de que seria efeito. Apenas isto.

De fato, o individualismo metodológico busca na referência ao mental individual - que está por trás do social, e o produz, deixando fortes marcas de origem - um maior rigor na construção teórica, para além de meras descrições e correlações. Na verdade, pode-se explicar o coletivo pelo coletivo apenas em um nível menos abrangente de explicação.

Embora haja propriedades emergentes (novas) do social em relação ao mental ${ }^{9}$, elas são fracas o suficiente para possibilitar uma explicação unitária do mental e do social, pois tudo indica que qualquer mental e qualquer social só é tal sendo do tipo siv; e, assim, os efeitos do mental e do social derivam dos efeitos dos elementos componentes de siv (sentimento, ideia e vontade). Sem prejuízo de leis menos gerais específicas da interação mental e da interação social.

Sem sentimento, ideia e vontade, não se tem basicamente o homem e o social produzido por ele. É preciso, pois, tratar sistematicamente a unidade siv como categoria social básica. Siste-

\footnotetext{
${ }^{3}$ LEVINE, Andrew; SOBER, Elliot; WRIGHT, Erik Olin. Marxism and methodological individualism. New Left Review, 162, march/april 1987. p. 6784.

${ }^{4}$ BAZARIAN, Jacob. Introdução à sociologia. As bases materiais da sociedade. São Paulo: Alfa-Omeg, 1982. p. 179.

${ }^{5}$ OLIVEIRA, Luciano. Não fale do Código de Hamurábi! A pesquisa sociojurídica na pós-graduação em Direito. In: comissário e outros ensaios de sociologia jurídica. Rio de Janeiro: Letra Legal, 2004. p. 141.

${ }^{6}$ STAMFORD DA SILVA, Artur. A decisão judicial: dogmatismo e empirismo. Curitiba: Juruá, 2000. p. 21-22.

${ }^{7}$ BOUDON, Raymond. Beyond rational choice theory. Annual Review of Sociology, 29, 2003. p. 3, 10.

${ }^{8}$ Cf. DURKHEIM, Émile. Les règles de la méthode sociologique. Paris: Presses Universitaires de France, 1968. p. $109,111$.

${ }^{9}$ Cf. OPP, Karl-Dieter. The individualistic research program in sociology. In: GERHARD, Radnitzky (Ed.). Centripetal forces in the sciences. New York:

Paragon House, 1988. v. II. p. 217.
} 


\subsection{TEORIA SOCIOJURÍDICA NACIONAL}

maticamente, e não apenas ocasionalmente.

A mencionada explicação unitária se poderia fazer muito rigorosamente, como um conjunto de definições e proposições, sendo que há proposições mais gerais e fundamentais (os postulados ou axiomas), e, destas, as restantes proposições (teoremas) são logicamente dedutíveis - é o que se chama axiomatização da pesquisa teórica. Essa forma rigorosa de apresentar a teoria já se encontra no sociólogo Homans ${ }^{10}$.

$\mathrm{Na}$ apresentação axiomática da construção teórica, reduzem-se não só as definições, mas se escolhe um determinado número de teses como postulados (o menor número possível). De tal sorte que todas as outras teses - teoremas - possam ser deduzidas dos postulados (proposições fundamentais) e nenhum postulado possa ser deduzido de outros postulados.

Será interessante notar que enquanto Udehn ${ }^{11}$ não acha frutífero procurar "a redução de leis sociais", Elster ${ }^{12}$ reconhece que a meta de estabelecer leis nas ciências sociais "sempre continuará [...] a guiar os estudiosos", preocupando-se em discutir maneiras de chegar-se a afirmações em forma de lei. Já Thye, referindo-se a áreas aplicadas (acordo comercial e negociação, justiça, poder, status e legitimidade), nota que "a pesquisa experimental tem resultado em teorias axiomáticas".

Mas como ter-se uma explicação científica rigorosa sem referência a proposições teóricas explicativas mais gerais que sejam comprováveis por pesquisa empírica: portanto sem a explicação da explicação, em terreno imediatamente anterior ao da Filosofia?

A explicação da explicação parece ser o problema crucial a ser enfrentado pela pesquisa científica substantiva sobre o direito neste início de século. Se pesquisas aplicadas são decerto válidas, o seu domínio quase exclusivo é seguramente índice de subdesenvolvimento teórico por carência de explicações causais mais gerais. Como, porém, superar essa situação atual de pobreza teórica da pesquisa sociojurídica? É o que tentaremos examinar em seguida.

\section{TENTANDO IR ALÉM DA POBREZA TE- ÓRICO-GERAL DA PESQUISA SOCIOJURÍ- DICA: CONSIDERAÇÃO PRELIMINAR}

Essa pobreza é clara e se liga à pobreza evidente do pensamento sociológico em geral ${ }^{14,15}$.

Assim, à pergunta "como se explica o fenômeno associativo humano?", poder-se-ia responder que esse fenômeno se deve a necessidades de alimentação, de agasalho e/ou abrigo, de defesa, ou a interesses econômicos, de poder político ou de prestígio intelectual e, na verdade, todos esses fatores e muitos outros têm sido causa do fenômeno grupal humano.

Essa maneira de explicar é válida por corresponder a fatores reais da associação humana. Contudo se aproximaria mais de uma enumeração descritiva de variáveis que de uma explicação científica rigorosa e abrangente. Esta última teria a forma de uma lei geral sobre o movimento de associação no espaço da interação social.

De fato, cada um dos fatores mencionados não explicaria sempre toda e qualquer espécie de movimento associativo: uma lei geral tentaria fazê-lo. Parece clara a conveniência teórica e prática da procura dessa lei.

$\mathrm{Na}$ verdade, existe atualmente um acentuado consenso de que um só tipo de fator concreto, social ou não, não é capaz de explicar, sozinho, em um determinismo unilateral, o processo social humano. Assim, já não caberia um determinismo ou de fatores geográficos, ou de fatores biológicos, ou de fatores econômicos etc.

Repare-se que a pesquisa científico-social, inclusive a pesquisa científico-social do direito, é

\footnotetext{
${ }^{10}$ HOMANS, George Caspar. Social behavior: its elementary forms. New York: Harcourt, Brace \& World, 1961. p. 2, 10, 31, 51-82, 205.

${ }^{11}$ UDEHN, Lars. The changing face of methodological individualism. Annual Review of Sociology, 28, 2002. p. 502.

${ }^{12}$ ELSTER, Jon. Alchemies of the mind: rationality and the emotions. Cambridge: Cambridge University Press, 1999. p. 1, 36 et seq.

${ }^{13}$ THYE, Shane R. Reliability in experimental sociology. Social Forces, 78 (4), june 2000. p. 1.302.

${ }^{14}$ Conferir, por exemplo: ELSTER, Jon. Alchemies of the mind: rationality and the emotions, p. 1, 36 et seq.; UDEHN, Lars. The changing face of methodological individualism. Annual Review of Sociology, 28, 2002. p. 502; BOUDON, Raymond. Beyond rational choice theory. Annual Review of Sociology, 29, 2003. p. 1-2. SZOSTAK, Rick. Classifying natural and social scientific theories. Current Sociology, v. 51 (1), jan. 2003. p. 44-46.

${ }^{15}$ Sobre como pensar sociologicamente, cf. SOUTO, Cláudio. O que é pensar sociologicamente. São Paulo: Pedagógica e Universitária, 1987, passim.
} 


\subsection{TEORIA SOCIOJURÍDICA NACIONAL}

uma atitude de conhecimento e nisso ela cumpre a missão que lhe é própria. Conhecida a realidade social de maneira científica tão rigorosa quanto possível, então é viável à ação prática social escolher, com base nesse conhecimento, ou sobretudo adaptar-se racionalmente a essa realidade; ou sobretudo transformá-la de modo racional. Pois sempre há, simultaneamente, adaptação à realidade social e sempre há transformação dela.

É necessário o afastamento de chavões pseudo-intelectuais esterilizantes. Ideia sem consideração da realidade não pode ser ideia científica. Realidade sem ideia não pode ser conhecimento.

À pesquisa científico-social do direito não cabe apenas definir, classificar e descrever, ou, mesmo, correlacionar fatos. Isso é importante, mas a alma da pesquisa científico-social está em explicar os fatos sociais concretos por proposições (teses) gerais, em forma de lei científica. O que é, essencialmente, um difícil trabalho de imaginação criadora.

Como, porém, fazê-lo, em termos de prática científica? É o que se verá a seguir.

\section{OS PASSOS PRÁTICOS PARA A BUSCA DA EXPLICAÇÃO CIENTÍFICO-SOCIAL MAIS ABRANGENTE DA PESQUISA EM DIREI- TO}

Os passos práticos no caminho mais geral e principal para a criação científica seriam, na devida ordem: observar informalmente o real, imaginar uma explicação para o observado, depois (e só depois) ler.

Antigo contemporâneo de estudos, Mozart Siqueira, insistia por este último passo. De fato, se intoxicarmos previamente nossa mente de ideias alheias sobre um determinado assunto, dificilmente ela terá (por forte influência de um alheio autoritativo) autonomia criativa.

Considera-se hoje experimentalmente comprovado que tão só por tomar conhecimento prévio da opinião de uma ou algumas pessoas, tende o sujeito a conformar-se ao julgamento alheio.

Ler, sim, e estrategicamente. Mas leríamos depois de termos, de modo provisório, tentado uma explicação que acreditamos própria. Essa leitura posterior nos iria informar se houve mesmo efetiva criação pessoal e sobre a valia do que eventualmente criamos.

O caminho da criação científica é como se fora uma via mais geral e principal à qual deveriam afluir todos os outros caminhos do pensamento científico.

Note-se que não parece ter maior significado que se construa teoricamente antes (ex ante) ou depois (ex post) de dados obtidos mediante técnicas de pesquisa. Naturalmente, a própria construção teórica ex ante, sendo científica, pressuporá algum grau de observação prévia informal da realidade. Depois ocorreriam as técnicas formais de pesquisa.

A construção ex ante pode conter proposições de tal modo estratégicas que o resto da construção possa ser deduzido delas rigorosa e elegantemente. E, quanto ao grau de criatividade, na construção ex ante estariam menos envolvidos condicionamentos prévios do pensamento criador, capazes de inibir ou diminuir a criatividade.

Em uma teoria científica mais geral do mental e do social (teoria unificada desses dois campos), estaria uma referência dotada de abrangência máxima explicativa quanto à pesquisa científica em direito. E lembre-se que a essa teoria lhe basta ser comprovável empiricamente. Assim, mesmo na Física, a teoria einsteiniana - a mais adequada até o momento -, sendo ela desde seu início comprovável, não teve uma comprovação empírica imediata e não a teve senão progressivamente.

\section{POSTULADOS DE INTERESSE EXPLI- CATIVO MAIS GERAL PARA A PESQUISA CIENTÍFICA EM DIREITO}

A mente humana se reduz essencialmente, ao que tudo indica, a sentimento, ideia e vontade (siv). Todo fenômeno mental e todo fenômeno social teria essa marca de origem. O mental seria basicamente o siv e o intersiv (sendo intersiv a interação entre polos mentais). O social seria 


\subsection{TEORIA SOCIOJURÍDICA NACIONAL}

o intersiv quando exteriorizado no espaço social (espaço de polos de interação social em comunicação siv).

De fato, tudo indica - insista-se - que sentimentos, ideias e volições existem, de modo acentuadamente básico, tanto na realidade individual, como na social (de tal sorte que uma explicação mais abrangente não poderia desconsiderar esses elementos). Quando interiorizados mentalmente, são elementos individual-psicológicos. Quando exteriorizados e recebidos pela comunicação, tornam-se fenômenos sociais e, se aceitos em comum por dois ou mais indivíduos (e se permanece o relacionamento sociointerativo), fenômenos grupais. O que é interiorizado em um momento pode ser exteriorizado em outro, e vice-versa: o que é mental pode tornar-se social, e inversamente.

Outros elementos básicos, por exemplo crença, pelas quais se interessa Boudon ${ }^{16}$, seriam derivados daqueles elementos fundamentais e, portanto, menos básicos ou abrangentes. Hoje é preciso reconhecer que o próprio grupo social, embora não se possa igualar à realidade mental individual, a tem em sua origem e apresenta claramente as marcas de sua origem, mesmo porque não existe mente grupal real, pois os grupos sociais não são entidades corpóreas: eles são o que é sentido, pensado e querido em comum por mentes individuais.

Os movimentos de atração e repulsão se fazem, de modo basilar, no caso humano, em relação ao siv, ao intersiv (interação mental) e ao intersiv exteriorizado (interação social).

O elemento $s$ (sentimento) se move basicamente em agradabilidade e em desagradabilidade, as quais ocorrem, respectivamente, em função da ideia de semelhança (agradabilidade) e de dessemelhança (desagradabilidade) com o que se aceita em um dado momento.

"Sentimento de justiça ou de justeza", "sentimento do belo", "sentimento de felicidade", "sentimento de paz", são expressões vocabulares, redutíveis todas, em termos científicos, a sentimento de agradabilidade.
Felicidade é simplesmente o sentimento de agradabilidade. Paz é simplesmente o sentimento suave e intenso de agradabilidade.

Repare-se: se o conflito (luta) é, dos processos de afastamento no espaço da interação social, o explicável pela maior ideia de dessemelhança entre os polos interagentes e, assim, o mais disfórico (desagradável) desses processos, no extremo oposto, a paz é o processo social de aproximação explicável pela maior ideia de semelhança entre os polos interagentes, e, desse modo, o mais eufórico (agradável) dos processos de aproximação, com o máximo de relativa suavidade afetiva. Um contínuo básico da distância social teria quatro polos, no sentido decrescente da distância: conflito, competição, cooperação e paz.

Mas como se processariam, tentando-se rigor axiomático, os movimentos de atração (aproximação) e de repulsão (afastamento) entre polos de interação mental (intersiv) e entre polos de interação social (intersiv exteriorizado)?

Cumpre não confundir: se não é possível um determinismo de fenômenos sociais particulares, como os econômicos, os políticos e até os de crença (que são mais gerais que os primeiros), pode muito bem existir um determinismo das categorias mais altamente genéricas, como ideia, sentimento, vontade, semelhança, distância mental, distância social. Categorias essas muitíssimo gerais, como energia, matéria, massa, distância física.

Todavia, considerando objetivamente semelhanças e dessemelhanças, o máximo que se poderia afirmar é que a semelhança provavelmente atrai e a dessemelhança provavelmente afasta. Assim, teríamos a proposição somente estocástica (somente probabilitária): quanto maior a semelhança objetiva entre polos interativos, mentais ou sociais, tanto menor, provavelmente, a distância entre eles.

Entretanto, tudo indica que é possível obter, quanto ao mental e ao social, pelo menos um determinismo subjetivo, isto é, baseado na avaliação subjetiva dos atores. De logo se observe que a muito abrangente ideia de semelhança com o

${ }^{16}$ BOUDON, Raymond. Interview: Cynthia Lins. [Texto digitado]. September, 21. Paris: 1995. p. 3. 


\subsection{TEORIA SOCIOJURÍDICA NACIONAL}

que se aceita - seja correta ou incorreta, racional ou irracional, essa ideia - sempre causaria aproximação nos espaços mental e social. As pessoas e grupos de qualquer tamanho sempre se aproximariam e sempre se afastariam do que, respectivamente, considerem mais semelhante ou mais dessemelhante do que aceitam.

E será viável obter até mesmo um determinismo objetivo, porque referido a sentimento (abstraído o elemento ideia), como se verá logo adiante.

Poderíamos, então, científica e deterministicamente, ter, sobre distância mental e sobre distância social, um postulado, isto é, uma proposição básica comprovada ou comprovável, da qual seria possível deduzir proposições menos gerais (teoremas). Esse postulado, de forma simplificada, seria o seguinte: quanto maior a semelhança entre um polo de interação mental ou de interação social (tal como avaliada por ele em função do que aceita) e outro ou outros polos de interação mental ou de interação social, menor a distância do primeiro em relação ao outro ou outros. Isso sempre ocorreria.

Essa lei poderia explicar qualquer movimento de aproximação no espaço da interação mental ou no espaço da interação social (máximo de abrangência nesses espaços).

Outro postulado, basicamente, porém não exclusivamente psicológico, seria ainda mais geral: quanto maior for a ideia de semelhança que o ator de uma conduta humana, mental ou social, tenha, maior a agradabilidade sentida por ele, $e$, quanto maior esta, mais será desejada por ele. Isso também sempre ocorreria (proposição determinística).

Poder-se-ia ter ainda um postulado, totalmente objetivo e determinístico, porque referido apenas a sentimento: o sentimento de agradabilidade, ou de preponderante agradabilidade, diante de algo, sempre causa, respectivamente, aproximação ou uma resultante de aproximação, em direção a esse algo, no espaço mental e no espaço social.

Em sentido inverso, sendo premissas a ideia de dessemelhança (com o que se aceita), ou a de- sagradabilidade do sentimento, os postulados explicariam qualquer movimento de afastamento no espaço mental ou no espaço social.

$\mathrm{Na}$ verdade, não parece racional a descrença pessimista quanto ao modelo dedutivo-nomológico $^{17}$, na medida em que ela repousa sobre a escassez ou falhas de leis até agora apresentadas sobre o social - e, poder-se-ia acrescentar, também sobre o mental -, pois isso não é necessariamente impeditivo de novas eventuais descobertas.

E caberia uma observação fundamental: a de que em ciência, o determinismo altamente provável tende a se aproximar da evidência - uma vez "descoberto" esse determinismo. A alta probabilidade paga o preço da aproximação da evidência. Esse mesmo preço se paga pelos postulados acima sugeridos. Mas também na Física isso pode ocorrer.

Como na clássica lei da gravitação universal de Newton: nesta lei, apesar de sua importância e elegância, no fundo se tenderia ao óbvio de que quanto mais massa e menos distância, mais atração. Ou como na importante equação da energia de Einstein, na qual permanece a tendência ao óbvio, pois a energia variaria na razão direta da massa e da velocidade.

Contudo, a obviedade só surge depois da "descoberta". Como lembrava Newton, "a Natureza se contenta com simplicidade, e não gosta da pompa de causas supérfluas"18. Não valeria isso também para a pesquisa científica do mental e do social?

\section{ALGUNS TEOREMAS DE INTERESSE EX- PLICATIVO MAIS GERAL PARA A PESQUI- SA EM DIREITO}

Trata-se agora de expor alguns teoremas de um modelo teórico-unificado mental-social, teoremas esses deduzidos dos postulados já referidos. Naturalmente outros teoremas - de interesse para a explicação mais geral da pesquisa em direito - são ainda dedutíveis.

\footnotetext{
${ }^{17}$ UDEHN, Lars. The changing face of methodological individualism. Annual Review of Sociology, 28, 2002. p. 502.

${ }^{18}$ NEWTON, Sir Isaac. Mathematical principles of Natural philosophy. Translated by Andrew Motte and revised by Florian Cajori. Chicago-LondonToronto: William Benton, Publisher, Encyclopaedia Britannica, Inc., 1955. p. 270.
} 


\subsection{TEORIA SOCIOJURÍDICA NACIONAL}

É de notar-se que aqueles axiomas (postulados) altamente genéricos abrangem simultaneamente o mental e o social, microfenômenos sociais e macrofenômenos sociais. Assim, a possibilidade de correspondente amplitude permanece aberta para muitos teoremas deduzidos ou dedutíveis deles, embora, é claro, teoremas sejam necessariamente menos genéricos que postulados.

Repare-se que se chamamos "direito" o composto siv (composto sentimento e ideia e vontade) cujo elemento s é sentimento de dever ser (= sentimento de agradabilidade $=$ sentimento de justiça ou de justeza) e cujo elemento i é conhecimento de acordo com a ciência empírica (fática), as proposições 1, 7, 8, 9 e 23, adiante mencionadas, seriam teoremas mais diretamente relativos a uma teoria científico-substantiva do direito, e também, embora menos diretamente, os teoremas $2,3,5,11,12,14-21^{19}$.

De interesse explicativo para a pesquisa em direito, alguns teoremas básicos em conexão com os postulados anteriormente mencionados seriam os seguintes (tal como expressos de maneira simplificada):

1. (Nos polos de interação mental ou social), o que se conhece como correspondente a padrões do correto e/ou do belo (aceitos pelo que conhece), sente-se como agradável e o oposto a isso como desagradável. E o sentimento é tanto mais agradável ou desagradável (respectivamente), quanto maior se considere a correção e/ou beleza ou incorreção e/ou não beleza.

2. Na interação mental ou social, se a ideia de semelhança (com o que é aceito pelos polos interagentes) prevalece sobre a ideia de dessemelhança, o respectivo sistema de interação está equilibrado (contrabalançado); e inversamente.

3. Na interação mental ou social, se há equilíbrio permanente do sistema interativo, o processo resultante é associativo (integrativo).

4. Na interação mental ou social, quanto maior a semelhança (preponderante) entre os polos interativos (tal como definida em função do que aceitam), tanto maior o equilíbrio do sistema correspondente de interação.

5. Se a ideia de semelhança entre polos interagentes é maior do que a necessária para o (simples) equilíbrio permanente do sistema de interação mental ou social, o processo mental ou social (resultante) é da maior agradabilidade (= maior suavidade afetiva $=$ paz).

6. Quanto maior a paz do sistema de interação mental ou social, maior o equilíbrio desse sistema.

7. Quanto maior a padronização (uniformização) do elemento "ideia" de polos interativos mentais ou sociais, tanto maior a semelhança entre esses polos e tanto maior o equilíbrio do sistema correspondente de interação.

8. Se polos interativos mentais ou sociais têm o seu elemento "ideia" padronizado de maneira científico-empírica, (nessa medida) há a máxima possibilidade de conviç̧ão de que esse elemento "ideia" corresponda à realidade e, portanto, a máxima possibilidade de padronização de tal elemento "ideia”; consequentemente, há a máxima possibilidade de equilíbrio do sistema correspondente de interação (= máxima possibilidade de paz).

9. Se um composto sentimento e ideia e vontade tem seu elemento "ideia" de acordo com a ciência empírica atual (menor possibilidade de imprecisão e incerteza), é aceito ou tende a ser aceito como obrigatório em um sistema de interatos mentais ou sociais.

10. Se polos interagentes têm o seu elemento ideia padronizado, inclusive científico-empiricamente, na extensão dessa padronização, o elemento sentimento, no sentido geral do sentimento de agradabilidade, é o fator principal da mudança (alteração menor ou maior) do sistema de interação mental ou social correspondente (e não já o elemento ideia que, nessa extensão, pode ser considerado uma constante).

11. Quanto maior o equilíbrio de um sistema de interatos mentais ou sociais, tanto mais prontamente ele controla qualquer acontecimento

\footnotetext{
${ }^{19}$ Sobre essa definição do direito, ver resumo em SOUTO, Cláudio. Ciência e saberes jurídicos: enfrentando o objeto. In: STAMFORD DA SILVA, Artur (Coord.). Sociologia do direito: na prática da teoria. Curitiba: Juruá, 2007. p. 25-36. Para uma análise da perspectiva, ver: OLIVEIRA, Luciano. Cláudio Souto: um pensador afável mas ousado. In: ___ (Coord.). Natureza, mente e direito: para além do usual acadêmico. Recife: Nossa Livraria, 2009, passim.
} 


\subsection{TEORIA SOCIOJURÍDICA NACIONAL}

que possa perturbar a ideia de semelhança integrativa do sistema.

12. Em uma interação mental ou social, quanto menor a distância do(s) polo(s) interativo(s) de outro(s) polo(s) interativo(s), tanto menos energia será necessária para comunicação e controle.

13. Na interação mental ou social da paz, há o mínimo de energia necessária para comunicação e controle.

14. Quanto mais a socialização (exposição a padrões sociais) se faça no sentido da semelhança entre polos de interação mental ou social, tanto maior o equilíbrio do sistema de interatos correspondente a tais polos.

15. Quanto mais a socialização se faça no sentido da semelhança entre polos de interação mental ou social, tanto mais paz.

16. Na medida em que a socialização se faça em termos de dessemelhança entre polos de interação mental ou social, nessa medida o(s) polo(s) assim socializado(s) tenderá (ão) a conduta desequilibrante do sistema de interatos correspondente àqueles polos.

17. No afastamento pela ideia de dessemelhança (com o que se aceita) entre polos interativos mentais ou sociais, quanto maior o afastamento maior a desagradabilidade. E quanto maior a desagradabilidade, tanto maior a tendência para o conflito (conflito mental: conflito interno, ou conflito social: luta).

18. Na aproximação pela ideia de semelhança (com o que se aceita) entre polos interativos mentais ou sociais, quanto maior a aproximação, maior a agradabilidade. E quanto maior a agradabilidade, tanto maior a tendência para a cooperação e a paz.

19. Quanto maior a cooperação e sobretudo quanto maior a paz, maior a estabilidade da integração mental e social. E quanto maior a competição ("luta pacífica", processo de afastamento nos espaços mental e social), maior a instabilidade da integração mental e social.

20. A competição e o conflito, que são pro- cessos de afastamento nos espaços mental e social, podem servir a processos associativos (integrativos) apenas no sentido de prevenir um afastamento ainda maior nesses espaços.

21. A intensidade de atração do composto siv (composto sentimento e ideia e vontade) comunicado na interação mental ou social é tanto maior quanto maior sejam a agradabilidade que lhe corresponda e a desagradabilidade que corresponda ao composto siv que lhe seja desviante.

22. Na interação mental ou social da paz há o máximo de intensidade de atração do composto siv comunicado.

23. Se um sistema de interatos mentais ou sociais é considerado essencialmente (principalmente) justo por um ou mais polos interativos (e portanto essencialmente semelhante ao que eles aceitam), tais polos experimentam uma situação de relativa e saudável suavidade afetiva. Caso contrário, as situações oscilantes de agradabilidade e desagradabilidade, sobretudo as de desagradabilidade, desde que não são situações relativamente suaves, favorecem condições patológicas no indivíduo e consequentemente no sistema sociointerativo.

Para uma noção do poder explicativo e da operacionalização experimental do presente modelo unificado, veja-se o que se escreveu sobre modelo teórico-geral do social ${ }^{20}$. Pois este último modelo e o unificado são claramente afins e só se distinguem pelo nível de generalidade. $\mathrm{O}$ modelo unificado tem muito alto poder explicativo, parecendo abranger toda a conduta humana.

\section{REFERÊNCIAS}

AARNIO, Aulis; ARNAUD-DUC, Nicole. Dogmatique juridique. Dictionnaire Encyclopédique de Théorie et de Sociologie $d u$ Droit, sous la direction de André-Jean Arnaud. Paris: Librairie Générale de Droit et de Jurisprudence, 1993.

\footnotetext{
${ }^{20}$ SOUTO, Cláudio. Axiomatic reason in sociology and in sociology of law. In: FARALLI, Carla; PATTARO, Enrico (Ed.). Reason in law. Proceedings of the Conference held in Bologna, 12-15 December 1984. Milano: Dott. A. Giuffrè Editore, 1988. v. III. p. 119-126 e SOUTO, Cláudio. Teoria sociológica geral: uma fundamentação mais abrangente. São Paulo: Pedagógica e Universitária, 2006. p. 182-208.
} 


\subsection{TEORIA SOCIOJURÍDICA NACIONAL}

BAZARIAN, Jacob. Introdução à sociologia. As bases materiais da sociedade. São Paulo: AlfaOmeg, 1982.

BOUDON, Raymond. Interview: Cynthia Lins. [Texto digitado]. September, 21. Paris: 1995.

Beyond rational choice theory. Annual Review of Sociology, 29, 2003.

DURKHEIM, Émile. Les règles de la méthode sociologique. Paris: Presses Universitaires de France, 1968.

ELSTER, Jon. Alchemies of the mind: rationality and the emotions. Cambridge: Cambridge University Press, 1999.

HOMANS, George Caspar. Social behavior: its elementary forms. New York: Harcourt, Brace \& World, 1961.

LEVINE, Andrew; SOBER, Elliot; WRIGHT, Erik Olin. Marxism and methodological individualism. New Left Review, 162, march/ april 1987.

NEWTON, Sir Isaac. Mathematical principles of natural philosophy. Translated by Andrew Motte and revised by Florian Cajori. ChicagoLondon-Toronto: William Benton, Publisher, Encyclopaedia Britannica, Inc., 1955.

OLIVEIRA, Luciano. Não fale do Código de Hamurábi! A pesquisa sociojurídica na pósgraduação em Direito. In: (Coord.). Sua excelência, o comissário e outros ensaios de sociologia jurídica. Rio de Janeiro: Letra Legal, 2004.

Cláudio Souto: um pensador afável mas ousado. In: (Coord.). Natureza, mente e direito: para além do usual acadêmico. Recife: Nossa Livraria, 2009.

OPP, Karl-Dieter. The individualistic research program in sociology. In: GERHARD, Radnitzky (Ed.). Centripetal forces in the sciences. New York:
Paragon House, 1988. v. II.

SOUTO, Cláudio. Oqueépensar sociologicamente. São Paulo: Pedagógica e Universitária, 1987.

Axiomatic reason in sociology and in sociology of law. In: FARALLI, Carla; PATTARO, Enrico (Ed.). Reason in law. Proceedings of the Conference held in Bologna, 12-15 December 1984. Milano: Dott. A. Giuffrè Editore, 1988. v. III.

Teoria sociológica geral: uma fundamentação mais abrangente. São Paulo: Pedagógica e Universitária, 2006.

Ciência e saberes jurídicos: enfrentando o objeto. In: STAMFORD DA SILVA, Artur (Coord.). Sociologia do direito: na prática da teoria. Curitiba: Juruá, 2007.

STAMFORD DA SILVA, Artur. A decisão judicial: dogmatismo e empirismo. Curitiba: Juruá, 2000.

SZOSTAK, Rick. Classifying natural and social scientific theories. Current Sociology, v. 51 (1), jan., 2003.

THYE, Shane R. Reliability in experimental sociology. Social Forces, 78 (4), june 2000.

UDEHN, Lars. The changing face of methodological individualism. Annual Review of Sociology, 28, 2002.

WEBER, Max. Rechtssoziologie (aus dem Manuskript herausgegeben und eingeleitet von Johannes Winckelmann). Neuwied: Hermann Luchterhand Verlag, 1960.

\section{Autor convidado}

